\title{
Improvement Detecting Method of Optical Axes Parallelism of Shipboard Photoelectrical Theodolite Based on Image Processing
}

\author{
Huihui Zou \\ China Satellite Maritime Tracking \& Control Department, Jiangyin, China \\ Email: huichou945@126.com
}

How to cite this paper: Zou, H.H. (2017) Improvement Detecting Method of Optical Axes Parallelism of Shipboard Photoelectrical Theodolite Based on Image Processing. Optics and Photonics Journal, 7, 127133.

https://doi.org/10.4236/opj.2017.78B017

Received: May 13, 2017

Accepted: August 7, 2017

Published: August 10, 2017

\begin{abstract}
An improvement detecting method was proposed according to the disadvantages of testing method of optical axes parallelism of shipboard photoelectrical theodolite (short for theodolite) based on image processing. Pointolite replaced 0.2 " collimator to reduce the errors of crosshair images processing and improve the quality of image. What's more, the high quality images could help to optimize the image processing method and the testing accuracy. The errors between the trial results interpreted by software and the results tested in dock were less than 10", which indicated the improve method had some actual application values.
\end{abstract}

\section{Keywords}

Improvement Detecting Method, Shipboard Photoelectrical Theodolite, Optical Axes Parallelism, Image Processing

\section{Introduction}

The optical axes parallelism is one of the vital indexes to evaluate the measurement precision of theodolite [1]. As the azimuth-zero set constant reference for the tracking \& control equipment, theodolite is a main calibration tool when the ship in dock.

A testing method of optical axes parallelism of shipboard photoelectrical theodolite was proposed in reference [2], which provided a new way under dynamic conditions. While the detection accuracy and efficiency of the method were limited by hardware and software in some way, it was necessary to apply an improvement detecting method to overcome those limitations. 


\section{Error Analysis of Image Processing}

In the former image processing method progress, CCDs were used to record the images or videos of the crosshair of 0.2 " collimator, and then the data stored in CCDs would be acquired by DAQ (Data Acquisition) cards and sent to computer, and the results would be calculated immediately. The whole progress was shown in Figure 1.

During the detecting processing, many factors such as hardware, experimental environment and the image processing calculation may affect the final result. According the analysis of factors mentioned above, some conclusion could come to as follows.

1) According to the imaging principle, the crosshair getting smaller when the axes of 0.2 " collimator further from the middle of Mid-Wave infrared visual field.

2) The CCD lens distortion was another crucial factor for the system precision.

3) The higher the resolution, the finer the detail that can be seen, error might be caused by resolution of image sensor in image acquisition system.

4) Noise source might cause noise during the images acquisition, which could not be denoise clearly.

5) In the process of image processing, many valid pixels might be lost, thus to improve the testing accuracy, optimized arithmetic should be applied.

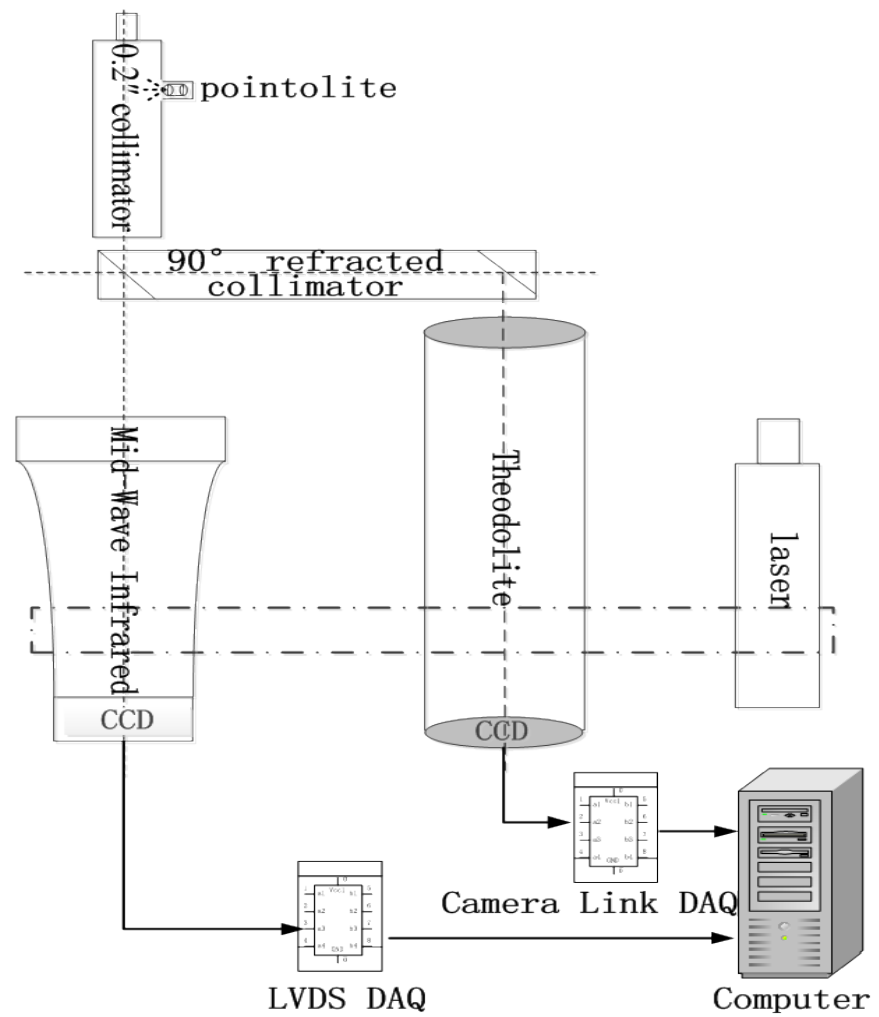

Figure 1. The former image processing method. 
The resolution of theodolite system was $0.44 "$, while the Mid-Wave infrared system was $15.5 "$, so the main factor that affected the system precision was image processing of Mid-Wave infrared system. Figure 2 demonstrated that the crosshair of 0.2 " collimator imaging in the theodolite system, which was not conducive to improve the accuracy of image processing.

Actually, during the experiment, the crosshair of 0.2 " collimator imaging in the Mid-Wave infrared was blurring. The analysis result indicated that when crosshair reflect through $0.2^{\prime \prime}$ collimator and $90^{\circ}$ refracted collimator, the illuminance and thermal radiation underwent great loss, consequently, images could not meet the accuracy requirement.

\section{Improvement Detecting Method of Optical Axes Parallelism}

Since images with low quality and image processing with low accuracy, some steps were taken to improvement light source and image processing method.

\subsection{Design of Detecting Method}

After theoretical analysis and study, two methods were intended to apply to replace 0.2 " collimator, which were laser combine with frequency multiplier and halogen tungsten lamp match with lens that can converge light [3]. By analyzing the scale of efficiency and cost of the two methods, halogen tungsten lamp match with lens would be the best choice. The result showed that the halogen tungsten lamp could image a small point in the Mid-Wave infrared CCD, hence, the image could be processed simply and conveniently. The experimental site and image in the Mid-Wave infrared CCD shown in Figure 3.

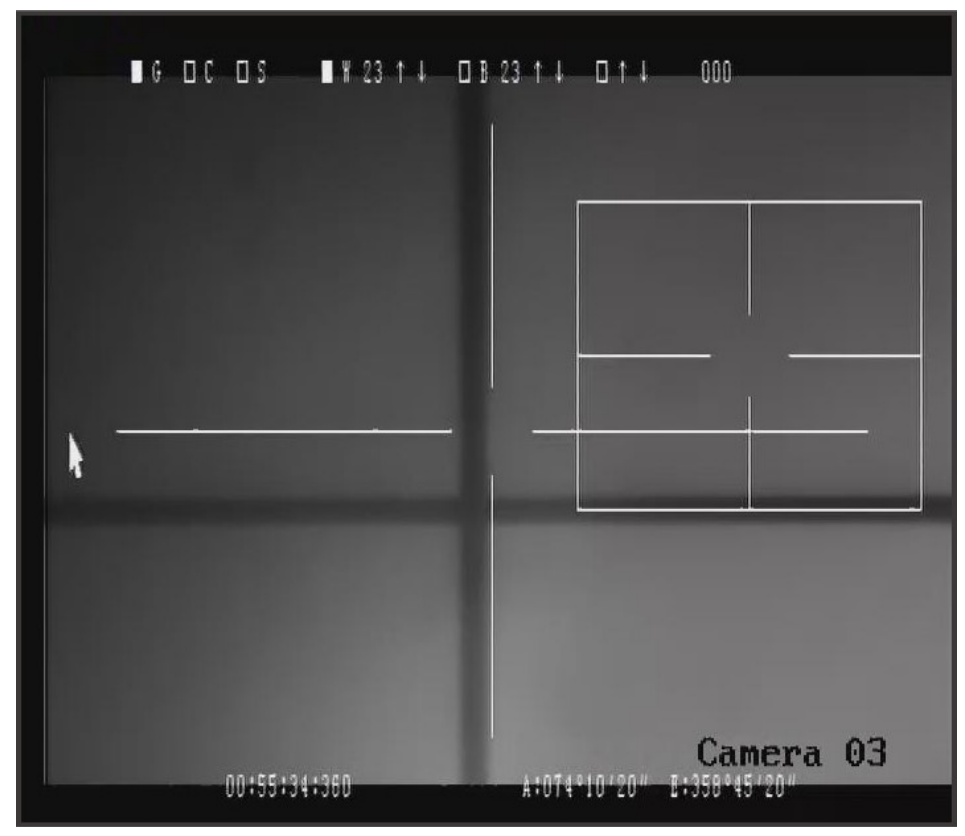

Figure 2. Image acquired by former image processing method. 

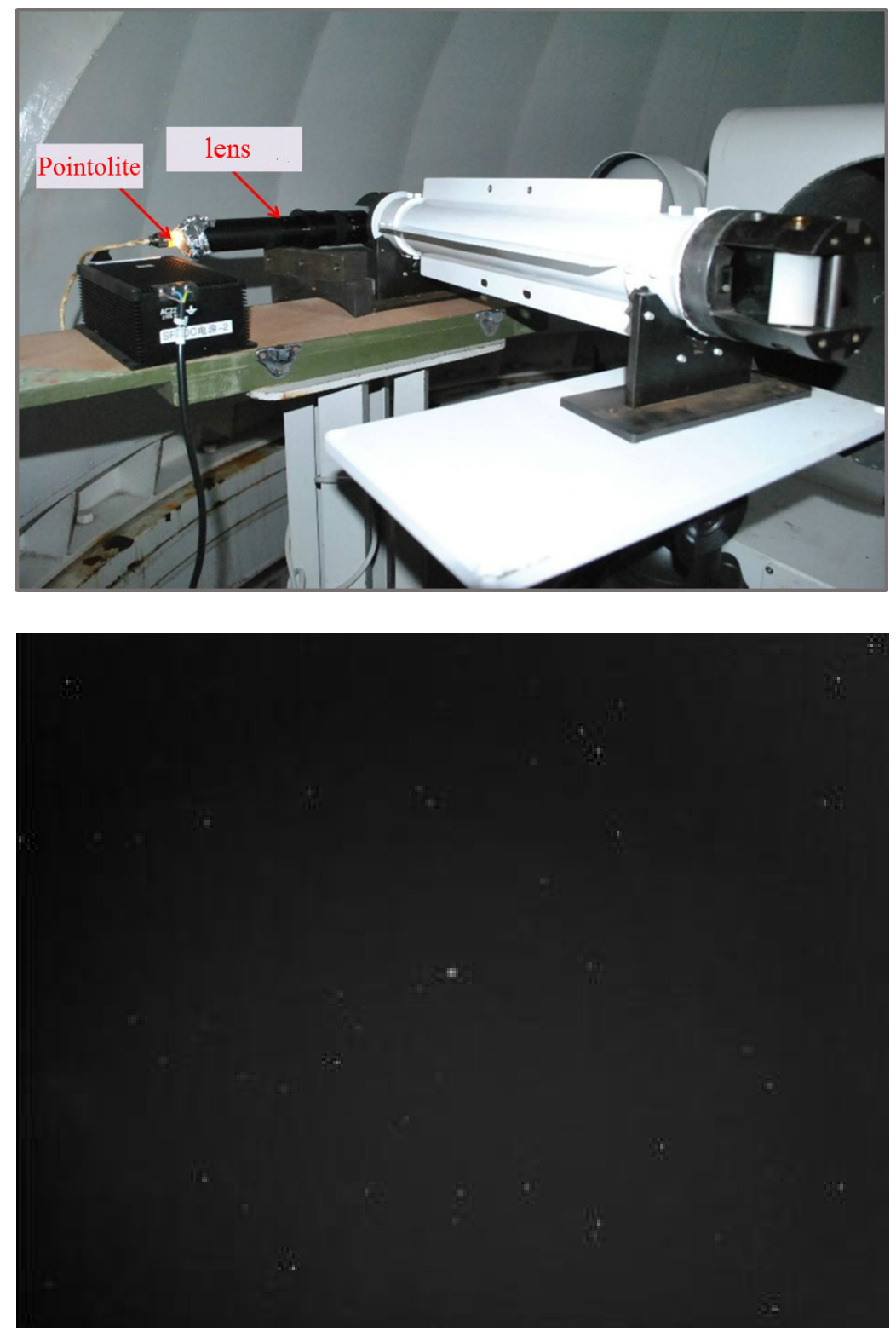

Figure 3. Program improvement test and result.

\subsection{Optical Axes Parallelism Test}

The experiment was carried on in the early morning, when tide and crew' activities had minimum effect on ship movement. Firstly, setting the testing support on the transition section of theodolite, and fixing the halogen tungsten lamp and lens in the testing support. Secondly, adjusting position between the lens and theodolite, till the point light in the vision field of Mid-Wave infrared CCD. Thirdly, adjusting the $90^{\circ}$ refracted collimator to support the point light into the vision field of theodolite CCD. And then, turning the computer power on, the camera link DAQ card and LVDS DAQ card started to acquire the images and store in the hardware. Finally, transmitting the point light imaged in the two systems to the software, where the middle of the point light would be calculated. 
By compared many advanced methods on image processing, the adaptive gradient threshold anisotropic filtering algorithm was chosen to suppress the infrared complex back-ground [4], filter out the noise effectively and enhance the point light target, and the result was shown in Figure 4(a). After filtering, mouse was used to click the centre of point light target, and the program could build a fixed window with 12 pixels $\times 12$ pixels for feature extraction, which was shown in Figure 4(b). Finally, centrobaric arithmetic was used to calculate the point light target in the fixed window, and the result was shown in Figure 4(c).

\subsection{The Result of Optical Axes Parallelism Test}

The optical axes parallelism could be expressed as follow formula according to principle of optical system [5].

$$
\left\{\begin{array}{l}
\Delta A=\frac{1}{n} \sum_{i=1}^{n}\left(x_{1 i} * \theta_{1}-x_{2 i} * \theta_{2}\right) \\
\Delta E=\frac{1}{n} \sum_{j=1}^{n}\left(y_{1 j} * \theta_{1}-y_{2 j} * \theta_{2}\right)
\end{array}\right.
$$

wherein, $\Delta A$ and $\Delta E$ were axes parallelism of azimuth axis and pitching axis of theodolite and Mid-Wave infrared optical systems, while $\theta_{1}$ and $\theta_{2}$ were angular resolution of the two optical systems, and $\mathrm{x}_{1}, \mathrm{x}_{2}$ were azimuth pixels of the two optical systems, similarly, $y_{1}, y_{2}$ were pitching pixels of the two optical systems, and $\mathrm{n}$ was data recording times.

The data in Table 1 was brought into Formula (1), then the optical axes parallelism of theodolite and Mid-Wave infrared optical systems is $(-18.89$ ", $-24.43 ")$.

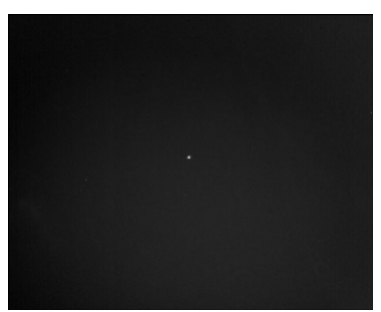

(a)

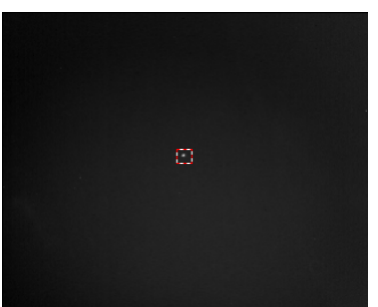

(b)

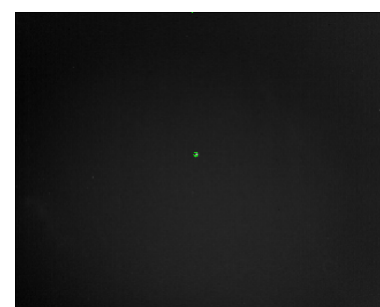

(c)

Figure 4. Target extraction processing. (a) Image denoise; (b) Fixed window; (c) Result achieved.

Table 1. Experimental results.

\begin{tabular}{ccccccc}
\hline \multirow{2}{*}{$\begin{array}{c}\text { Pixels } \\
\text { record times }\end{array}$} & \multicolumn{2}{c}{ Theodolite } & \multicolumn{2}{c}{ Mid-Wave infrared } & \multicolumn{2}{c}{ Optical axes parallelism (") } \\
\cline { 2 - 7 } & $\mathrm{x}_{1}$ & $\mathrm{y}_{1}$ & $\mathrm{x}_{2}$ & $\mathrm{y}_{2}$ & $\Delta \mathrm{X}$ & $\Delta \mathrm{Y}$ \\
\hline 1 & 254 & 116 & 8 & 5 & -12.24 & -26.46 \\
2 & 264 & 121 & 9 & 5 & -23.34 & -24.26 \\
3 & 248 & 90 & 8 & 4 & -14.88 & -22.4 \\
4 & 260 & 85 & 9 & 4 & -25.1 & -24.6 \\
\hline
\end{tabular}




\section{Error Analysis and Results Comparison}

\subsection{Relationship between Optical Axes Parallelism and Angle Measurement Error}

Relationship between optical axes parallelism of the two optical systems and angle measurement error could be expressed as Formula (2) [6].

$$
\left\{\begin{array}{l}
\delta_{\mathrm{A}}=\Delta A \\
\delta_{E}=\Delta E / \cos E_{c}
\end{array}\right.
$$

wherein, $\delta_{\mathrm{A}}$ and $\delta_{E}$ were the error caused by optical axes parallelism, while $E_{c}$ was elevation angle of theodolite.

\subsection{Results Comparison of Image Processing}

Image processing method was the key technology which had main effect on detection accuracy. A video and image processing software was used to detect the images which also processed by the improvement image processing method. The software could judge the change of miss distance of target by dealing with continuous frames images, which would help to eliminate the error caused by small displacement of target. The judgement of software had two methods, which were manual and automatic. Manual way was used to process fine and homogeneous target, which could achieve high image processing precision. The experiment was carried on under quasi-static condition, as a result, the ship swung periodically, similarly, the miss distance of target was periodic. The square root of the average of squares of miss distance could truly reflect the position of target. The real-time result was shown in Figure 5.

Series images were proceed by sending to the software as shown in Figure 6 which recorded in 5 minutes. The processing results showed that the miss distance of Mid-Wave infrared target was (-14.21", $-17.02 ")$, which within 10" of

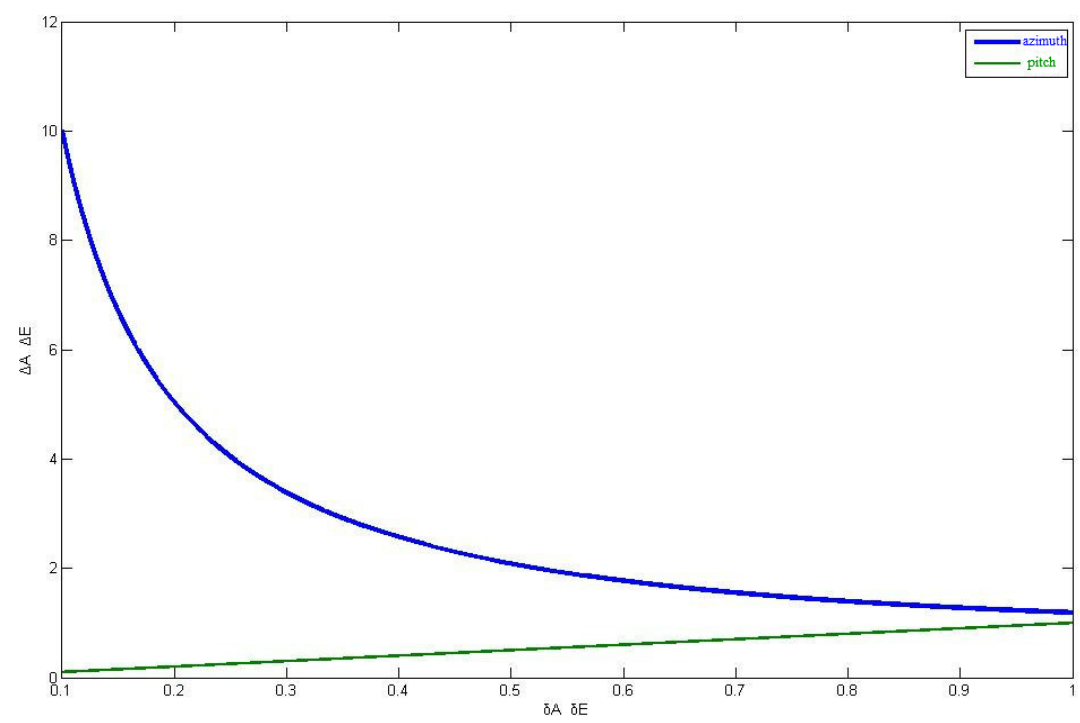

Figure 5. Relation graph of optical axes parallelism and angle measurement error. 


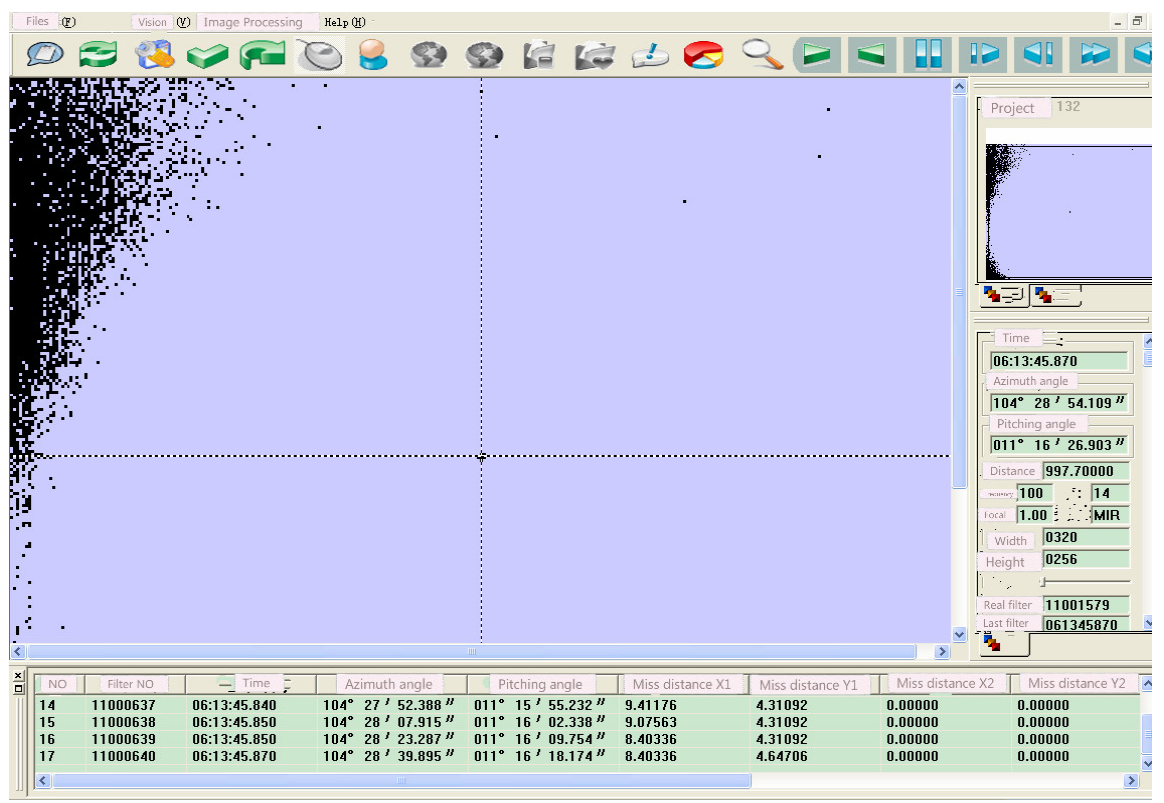

Figure 6. Processing results of software.

the result of this experiment.

\section{Application and Prospect}

The experiment showed that the improvement detection method improved imaging quality and optimized the image processing steps, which ensured its high precision and real-time performance. The follow-up work was accuracy verification, which should be carried out in the four quadrants of CCD, and accuracy verification results determined according to the consistency of the error.

\section{References}

[1] Zhong, D.A. (2009) Calibration Technology of TT\&C Equipment of Space Tracking Ship. National Defense Industry Press, Beijing.

[2] Zou, H.H., Wu, H.B. and Zhou, L.J. (2016) A Testing Method of Optical Axes Parallelism of Shipboard Photoelectrical Theodolite. Advanced Optical Manufacturing and Testing Technologies, Suzhou.

[3] Zhang, T.M., Wu, Y.F. and Zhang, P. (2014) Investigation of Intensity Distribution by Laser Frequency Doubling Technology Based on Matlab. Experimental Technology and Management, 31, 53-54.

[4] Sun, H.J., Wang, Y.J. and Chen, X.L. (2014) Suppression of Infrared Complex Background Based on Adaptive Gradient Threshold Anisotropic Filtering. Optics and Engineering, 22, 147-151.

[5] Leng, J., Liu, B.Q. and Zhao, X.L. (2003) The Comparison and Discussion of Several Methods about Optical Axis Parallelism. Journal of Applied Optics, 24, 43-44.

[6] Liu, L.S. (2000) The Process of Tracking Data. National Defense Industry Press, Beijing, 123-124. 
Submit or recommend next manuscript to SCIRP and we will provide best service for you:

Accepting pre-submission inquiries through Email, Facebook, LinkedIn, Twitter, etc. A wide selection of journals (inclusive of 9 subjects, more than 200 journals)

Providing 24-hour high-quality service

User-friendly online submission system

Fair and swift peer-review system

Efficient typesetting and proofreading procedure

Display of the result of downloads and visits, as well as the number of cited articles Maximum dissemination of your research work

Submit your manuscript at: http://papersubmission.scirp.org/

Or contactopj@scirp.org 